\title{
Stable predictive markers for Phytophthora sojae avirulence genes that impair infection of soybean uncovered by whole genome sequencing of 31 isolates
}

Geneviève Arsenault-Labrecque ${ }^{1}$, Humira Sonah¹, Amandine Lebreton', Caroline Labbé', Geneviève Marchand², Allen Xue ${ }^{3}$, François Belzile ${ }^{1}$, Brian J. Knaus ${ }^{4}$, Niklaus J. Grünwald ${ }^{4}$ and Richard R. Bélanger ${ }^{1 *}$ (id

\begin{abstract}
Background: The interaction between oomycete plant pathogen Phytophthora sojae and soybean is characterized by the presence of avirulence (Avr) genes in P. sojae, which encode for effectors that trigger immune responses and resistance in soybean via corresponding resistance genes (Rps). A recent survey highlighted a rapid diversification of $P$. sojae Avr genes in soybean fields and the need to deploy new Rps genes. However, the full genetic diversity of P. sojae isolates remains complex and dynamic and is mostly characterized on the basis of phenotypic associations with differential soybean lines.

Results: We sequenced the genomes of 31 isolates of $P$. sojae, representing a large spectrum of the pathotypes found in soybean fields, and compared all the genetic variations associated with seven Avr genes (1a, 1b, 1c, 1d, 1k, 3a, 6) and how the derived haplotypes matched reported phenotypes in 217 interactions. We discovered new variants, copy number variations and some discrepancies with the virulence of previously described isolates with Avr genes, notably with Avr1b and Avr1c. In addition, genomic signatures revealed 11.5\% potentially erroneous phenotypes. When these interactions were re-phenotyped, and the Avr genes re-sequenced over time and analyzed for expression, our results showed that genomic signatures alone accurately predicted $99.5 \%$ of the interactions.

Conclusions: This comprehensive genomic analysis of seven Avr genes of $P$. sojae in a population of 31 isolates highlights that genomic signatures can be used as accurate predictors of phenotypes for compatibility with Rps genes in soybean. Our findings also show that spontaneous mutations, often speculated as a source of aberrant phenotypes, did not occur within the confines of our experiments and further suggest that epigenesis or gene silencing do not account alone for previous discordance between genotypes and phenotypes. Furthermore, on the basis of newly identified virulence patterns within Avr1C, our results offer an explanation why Rps $1 \mathrm{c}$ has failed more rapidly in the field than the reported information on virulence pathotypes.
\end{abstract}

Keywords: Avr genes, Effectors, Genomics, Haplotype analysis, Oomycete, Phytophthora sojae, Plant pathogen, R genes

\footnotetext{
* Correspondence: richard.belanger@fsaa.ulaval.ca

'Département de Phytologie, Université Laval, Québec, QC, Canada

Full list of author information is available at the end of the article
}

(c) Belanger et al. 2018 Open Access This article is distributed under the terms of the Creative Commons Attribution 4.0 International License (http://creativecommons.org/licenses/by/4.0/), which permits unrestricted use, distribution, and reproduction in any medium, provided you give appropriate credit to the original author(s) and the source, provide a link to the Creative Commons license, and indicate if changes were made. The Creative Commons Public Domain Dedication waiver (http://creativecommons.org/publicdomain/zero/1.0/) applies to the data made available in this article, unless otherwise stated. 


\section{Background}

Phytophthora sojae (Kauf. \& Gerd.), a hemibiotrophic oomycete causing root and stem rot in soybean, is among the top 10 plant-pathogenic oomycetes/fungi of both scientific and economic importance [1]. Management of $P$. sojae relies mostly on the development of cultivars with major resistance (Rps) genes. The development of root and stem rot caused by $P$. sojae is determined by the gene-for-gene relationship between resistance (Rps) genes in soybean and their matching avirulence $(A v r)$ genes in the pathogen. Typically, Rps genes encode, or are predicted to encode for proteins having nucleotide-binding site and leucine-rich repeat (NLR receptors) while $P$. sojae Avr genes code for small effector proteins mostly with RXLR and DEER amino acid motifs. In such cases, NLR receptors from soybean recognize the RXLR effectors encoded by Avr genes from $P$. sojae, inducing an appropriate defense response [2, 3]. The pathogen can avoid recognition conferred by Rps genes through various mutations such as a substitutions, frameshift mutations, partial or complete deletions, large insertions, recombinations, or changes in expression of $A v r$ genes [4].

To date, over 27 major Rps genes have been identified in soybean [2] and about 12 Avr genes have been identified and characterized in P. sojae [5-9]. Most of the Avr genes are clustered together on $P$. sojae chromosomes, and many of them are candidate paralogs. For instance, Avr1a and Avr1c have very similar sequences [10]. In addition, some of the gene pairs earlier thought to be different genes, such as Avr3a/Avr5 and Avr6/Avr4, turned out to be different alleles of the same gene [11, 12]. In the case of Avr1a, deletion of two out of four nearly identical copies of the gene has been found to cause virulence. Similarly, some P. sojae strains have as many as four paralogs of $A v r 3 a$, and some have only one [13]. Such high levels of similarity, tandem duplications, and variation in the number of copies make it very difficult to develop sequence-based diagnostic markers.

Avirulence (Avr) genes from Phytophthora species are mostly located in highly dynamic genome areas containing duplications and repetitive sequences that are prone to chromosomal rearrangements [4]. Characterization of such loci needs high-quality sequencing with "border" coverage and high depth. High levels of sequence variation, duplications, interdependency of Avr genes, and rapid evolution complicate the task of characterizing newly evolved strains. With approximately 20.5 million metric ton losses attributed to Phytophthora root and stem rot since 1996, efficient tools to rapidly and accurately identify virulence features in $P$. sojae have become essential to prevent disease outbreaks [14]. In this regard, recent advances in sequencing technology provide the opportunity to perform whole genome sequencing (WGS) of multiple strains. This approach facilitates the identification of all potential variations, and chromosomal rearrangements, and can be used for the identification of variation signatures (haplotypes) associated with virulence factors [15]. Haplotypes representing the allelic variation of a given gene have also been found to be tightly linked with the copy number variation and expression of the same gene [15-17]. Na et al. [10] identified Avrla and Avrlc as a pair of tandem duplicated genes near the Avr1c locus by using a WGS approach.

Apart from the need for high-quality sequencing to decipher Avr genes, precise phenotyping of the interactions between pathotypes and differentials remains an essential component to assess the functionality of either $A v r$ or Rps genes. For this purpose, several phenotyping methods have been developed and proposed [18-23]. Over the years, the hypocotyl inoculation test has become the standard test, particularly because of its ease of use [24]. However, as convenient as the hypocotyl inoculation method is, it has limitations leading to the identification of false positives or negatives [25], which can bring confusion about the presence and/or functionality of Avr genes in P. sojae isolates. Recently, Lebreton et al. [26] used a simplified hydroponic assay to more robustly characterize the phenotypes by inoculating the root system of soybean plants directly with zoospores of $P$. sojae. It thus offers a potentially better option to link phenotypes with genotypes of tested P. sojae isolates.

In the present study, a diverse set of $31 P$. sojae isolates representing the range of pathotypes commonly observed in soybean fields was sequenced using WGS. To understand the evolution and genetic constitution of $P$. sojae strains, haplotype analyses using the WGS data were performed for the seven most important $A v r$ genes found in $P$. sojae populations: $1 \mathrm{a}, 1 \mathrm{~b}, 1 \mathrm{c}, 1 \mathrm{~d}$, $1 \mathrm{k}, 3 \mathrm{a}$, and 6 . Our data provide new insights into the complexity of $A v r$ genes and their associated functionality and reveal that their genomic signatures can be used as accurate predictors of phenotypes for interaction with Rps genes in soybean.

\section{Results \\ Sequencing and mapping}

A total of 852,950,094 reads were obtained from paired-end sequencing of the $31 \mathrm{P}$. sojae isolates on the Illumina HiSeq 2500 sequencer. The number of sorted raw sequence reads per isolate ranged from 15 to $52 \mathrm{M}$ reads with an average of $27 \mathrm{M}$ reads per isolate, with a mean Phred-score of 32.4. Reads were processed using Trimmomatic, and the processed reads were mapped to the reference genome [27]. For every isolate, more than $96 \%$ of the reads were accurately mapped to the reference genome with a mean depth coverage of $68 \times$. 


\section{Coverage, distribution, and predicted functional impact of SNPs}

The HaplotypeCaller pipeline from GATK retained 260,871 variants among the 31 isolates. Stringent filtering of the variants based on sequence depth and mapping quality using vcfR retained a total of 204,944 high-quality variants. Variant analysis with SnpEff tool [28] identified 172,143 single nucleotide polymorphisms (SNPs), 14,627 insertions, and 18,174 small indels in the total number of variants. Variants in coding regions were categorized as synonymous and non-synonymous substitutions; $61.1 \%$ of the SNPs resulted in a codon that codes for a different amino acid (missense mutation; $59.5 \%$ ) or the introduction of a stop codon (nonsense mutation $1.6 \%$ ), whereas the remaining $38.9 \%$ of the SNPs were considered to be synonymous mutations.

\section{Phylogenetic analysis}

A phylogenetic tree was first constructed with all 204,944 variants among the 31 isolates. Results showed that, based on whole-genome data, no general inference could be made on the relationship between the virulence profiles of all isolates and their genetic variability, except for those of race 7 (Fig. 1a). A second phylogenetic tree was then constructed with variants belonging only to the seven $A v r$ genes used to define those virulence profiles (Fig. 1b). This highlighted a certain level of clustering based on the virulence profile of the isolates while some discrepancies were noted. For example, isolates $25 \mathrm{C}$ did not cluster with other isolates from the same virulence profile $(25 \mathrm{~B}$ and $25 \mathrm{D})$ or isolates from race $8(8 \mathrm{~A}, 8 \mathrm{~B}$, and $8 \mathrm{C}$ ) were all found on different branches of the tree. Links among the seven Avr genes were then further investigated on the basis of haplotype analysis.

\section{Haplotypes for Avr1a}

For all 31 isolates, CNV was analyzed based on depth of coverage and, for Avr1a, it ranged between zero and three copies (Fig. 2b). Among isolates with zero copy, all were virulent on Rps1a. For the remaining isolates, no SNPs or indels were observed within the coding region of Avr1a (Fig. 2a). However, we observed SNPs flanking Avrla that were in high linkage disequilibrium (LD) $\left(R^{2} \geq 0.7\right)$ and defined four distinct haplotypes (Fig. 2b). Additional variants were also found but did not offer a higher level of discrimination (Additional file 1). All isolates sharing three of these $(B, C$, and $D)$ were virulent on Rps1a while among isolates with haplotype $\mathrm{A}$, all but isolate $3 \mathrm{~A}$ were incompatible based on the hypocotyl assay. After re-phenotyping this isolate with the hydroponic bioassay, it was characterized as being unable to infect the differential carrying Rps1a confirming that haplotype A was the only one associated with an incompatible interaction with Rps1a (Fig. 2c).

\section{Haplotypes for Avr $1 b$}

No CNVs or deletions were observed for Avr1b (Fig. 3a). Within the coding region of the gene, 17 variants were observed: 14 missense variants (SNPs), two small indels of three nucleotides each, and one synonymous SNP (Additional file 1). None of these variants were predicted to have a high functional impact. Based on the LD between these variants, two tag variants were retained and defined three haplotypes (Fig. 3b). Most isolates of haplotypes $\mathrm{A}$ and $\mathrm{B}$ were avirulent while all isolates with haplotype $\mathrm{C}$ were virulent. Among haplotypes $\mathrm{A}$ and $\mathrm{B}$, four isolates with a discordant phenotype were re-tested with the hydroponic assay and were found to be avirulent to Rps1b (Fig. 3c), confirming haplotypes $\mathrm{A}$ and $\mathrm{B}$ as being associated with an incompatible interaction
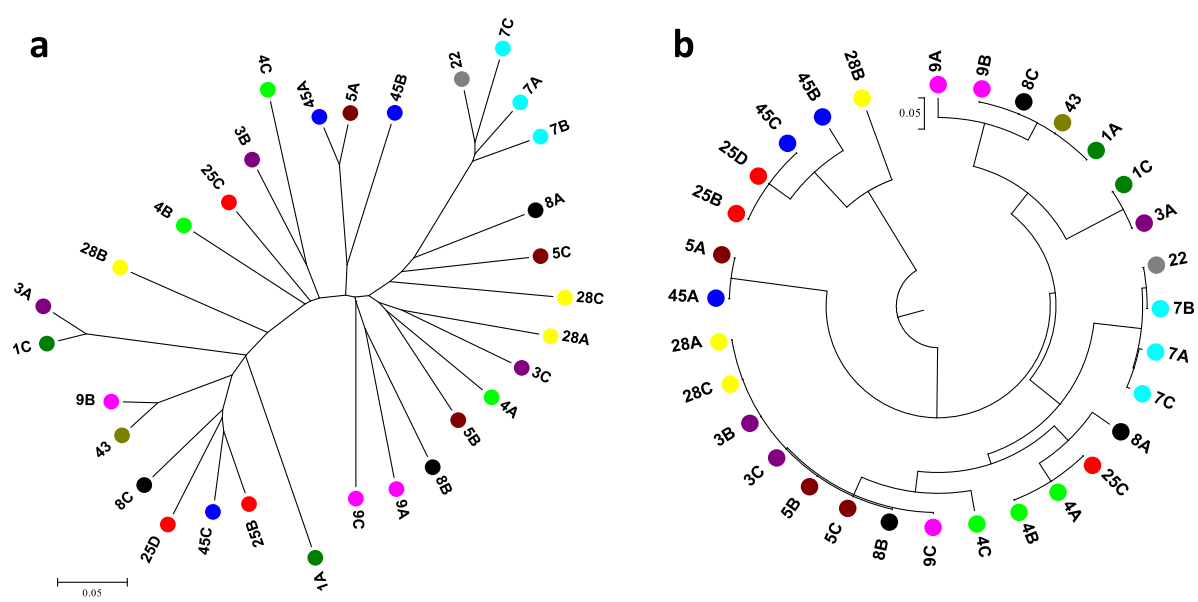

Fig. 1 Phylogenetic analysis from variants among 31 isolates of Phytophtora sojae. a Neighbor-joining tree using whole-genome data. b Neighbor-joining tree using variants within seven Avr genes region (1a, 1b, 1c, 1d, 1k, 3a, 6). Each isolate is color-coded based on its initial virulence profile (from the hypocotyl test: see Table 2) 


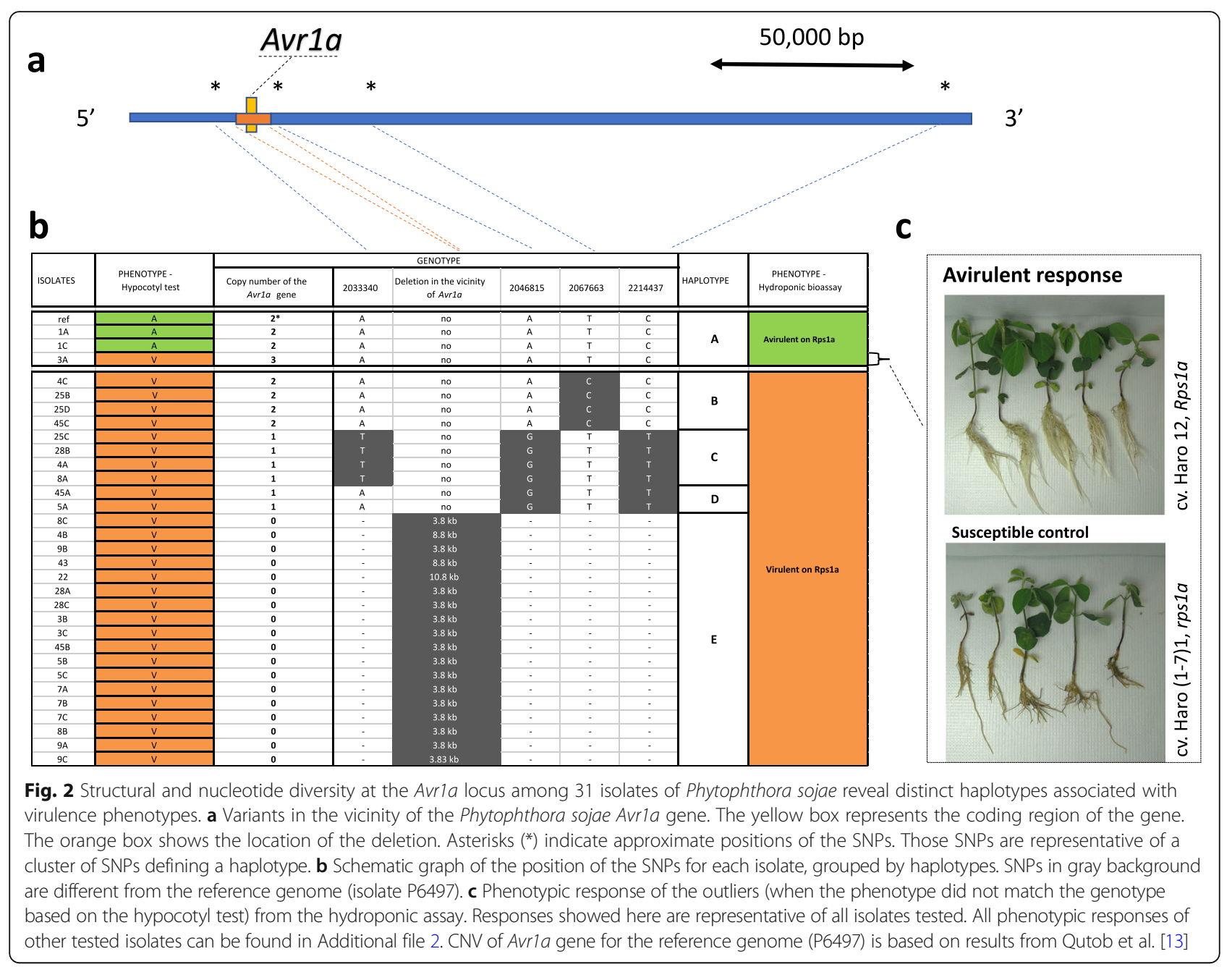

with Rps1b (Fig. 3b) in our study. To verify that the genotype of these four isolates had not changed over time, we re-sequenced the $A v r 1 b$ region of these isolates together with representative isolates from each haplotype group and P6497 and confirmed the same mutations. On the other hand, P6497 used for the reference genome, associated with haplotype $\mathrm{A}$, did show a phenotype of virulence when assayed in the hydroponic system (Fig. 3c).

\section{Haplotypes for Avr1c}

Copy number variation was observed for Avr1c; complete deletion of the Avrlc gene was observed in three isolates while others presented one or two copies of the gene (Fig. 4b). Interestingly, this deletion is the same reported earlier for the Avrla gene that immediately flanks $A v r 1 c$ (Figs. $2 \mathrm{~b}$ and $4 \mathrm{~b}$ ). The remaining isolates presented a total of 24 variants within the coding region of the gene; two were synonymous while the rest were missense mutations, none of which being predicted to have a high functional impact (Additional file 1). After removal of redundant markers (based on LD), a total of four tag variants defined four haplotypes (A to D; Fig. 4b). Haplotypes $\mathrm{C}$ and $\mathrm{D}$ were shared by isolates that had a consistent phenotype, avirulent and virulent, respectively (Fig. 4b). Haplotype $\mathrm{C}$ was also the only haplotype to present a majority of heterozygous SNPs. In contrast, haplotype A was shared by five isolates previously phenotyped as avirulent to Rps1c and four phenotyped as being virulent. All nine isolates were re-phenotyped in the hydroponic assay, and the results showed a clear association with virulence to Rps1c (Fig. 4c). In addition, P6497 (ref) associated with haplotype A and a phenotype of avirulence was found to be virulent to Rps1c when phenotyped in the hydroponic assay. For haplotype B, most isolates were phenotyped as avirulent to Rps1c, with the exception of three isolates (5B, $5 \mathrm{C}$, and $45 \mathrm{~B})$ originally labeled as virulent. Variants within a $1-\mathrm{kb}$ upstream or downstream region of the gene could not define new haplotypes for these three outliers. These three isolates were re-phenotyped using the hydroponic bioassay and were still characterized as virulent (Fig. 4c). To further investigate the cause of this 


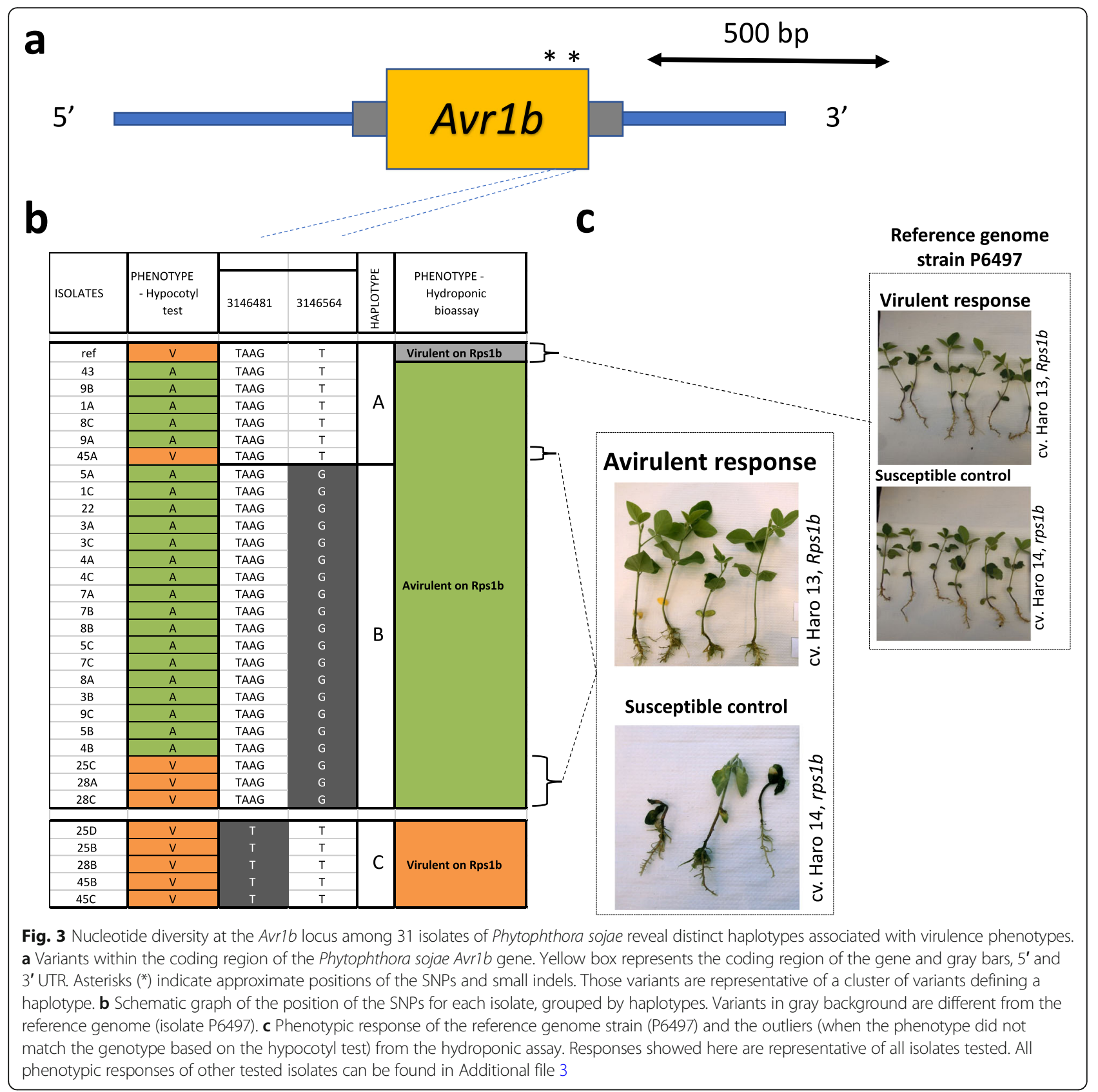

discrepancy, the Avrlc region for representative isolates from each haplotype group, including initial outliers from haplotype A, was re-sequenced using Sanger sequencing and confirmed the same mutations.

In order to determine if differences in gene expression could explain the aberrant phenotype, a qPCR-based gene expression analysis was performed. Interestingly, the expression of $A v r 1 c$ in isolates 5B, 5C, and 45B was significantly lower than that in the avirulent isolate, $28 \mathrm{~A}$, which would explain their virulence (Fig. 5). Attempts were then made to find distant variants associated with lower expression via genome-wide sequence comparison.
A total of 690 unique mutations, present in isolate 5B and absent in all other isolates of the same haplotype, were identified. Most of these were in non-coding regions, but five frameshift variants and two inframe deletions were observed, including a deletion of 29 bases in the $A v h 220$ gene (coding for an effector) were found to be unique to $5 \mathrm{~B}$. For isolate $5 \mathrm{C}$, a total of 473 unique mutations were observed including a 9-bp deletion in the Sin3 transcription factor that was unique to this isolate (Additional file 2). Finally, for isolate 45B, over 1000 unique mutations were observed including four in-frame deletions and ten stop/gain mutations. However, none 


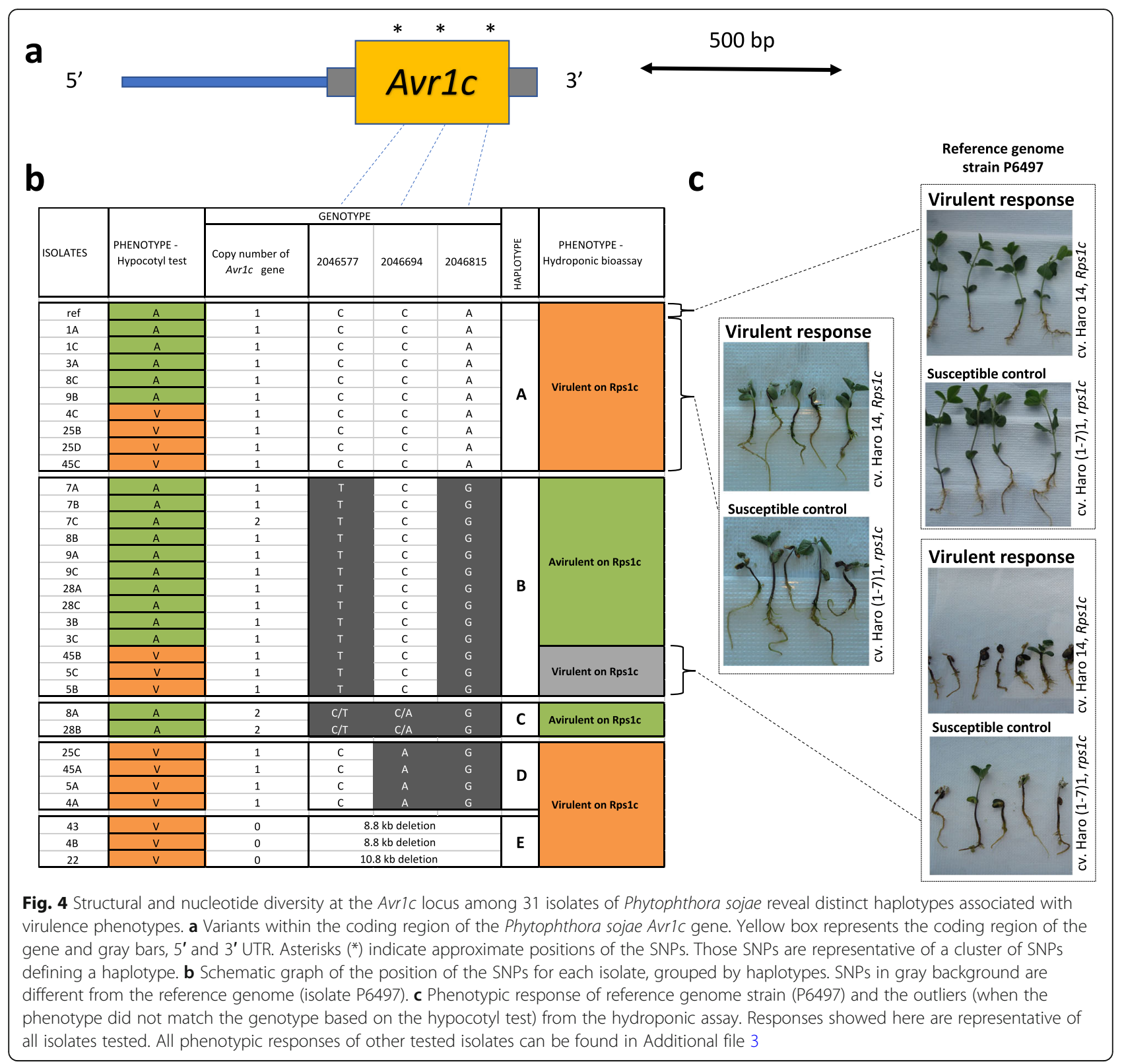

could be clearly linked with the lower expression of Avrlc in this isolate.

\section{Haplotypes for Avr1d}

A complete deletion of the Avrld gene was observed for seven isolates (Fig. 6b). The deletion encompassed both the upstream and downstream regions of the gene for a total deletion size of $2.3 \mathrm{~kb}$, with another upstream deletion of $0.8 \mathrm{~kb}$, separated by a segment of $177 \mathrm{bp}$ (Fig. 6a). The remaining isolates presented one copy of the gene, and 21 variants were observed within the coding region: one was synonymous while the others were missense variants, none of which were predicted to have a high functional impact (Additional file 1). Based on LD, one tag variant was retained and two haplotypes (A and B) could be defined. Genomic data coincided with the original phenotypes based on the hypocotyl assay in 25 out of 31 interactions. However, from the original phenotyping by Xue et al. [29], two isolates predicted to be avirulent based on the genotype were phenotyped as virulent and four isolates predicted as virulent were phenotyped as avirulent. When these isolates were phenotyped with the hydroponic assay, all the isolates with a predicted genotype of virulence were consistenly associated with virulence while the isolate expected to be avirulent based on the haplotype was phenotypically avirulent, confirming that deletion of Avrld is consistently linked to virulence (Fig. 6). 


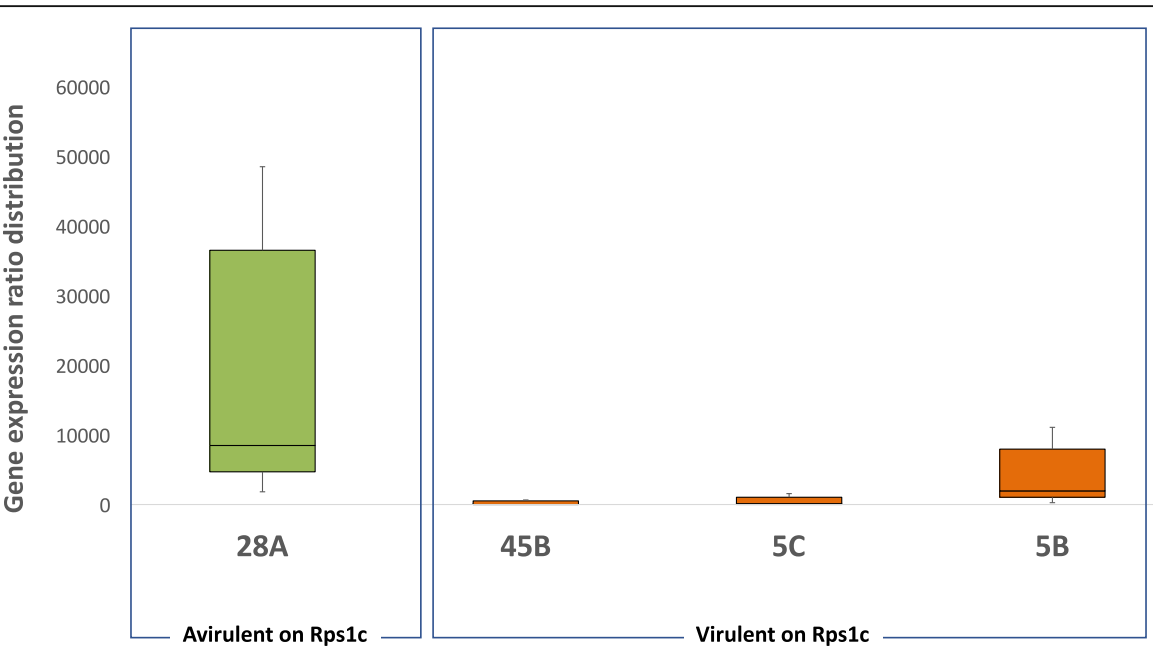

Fig. 5 Relative expression of the Phytophthora sojae Avrlc gene measured by real-time quantitative PCR in avirulent and virulent isolates. Fold change was based on gene expression ratio with virulent isolate 4C. Actin was used as an internal control to normalize gene expression. Bars represent standard error from the mean $(n=4)$. Individual values for every samples can be found in Additional file 5

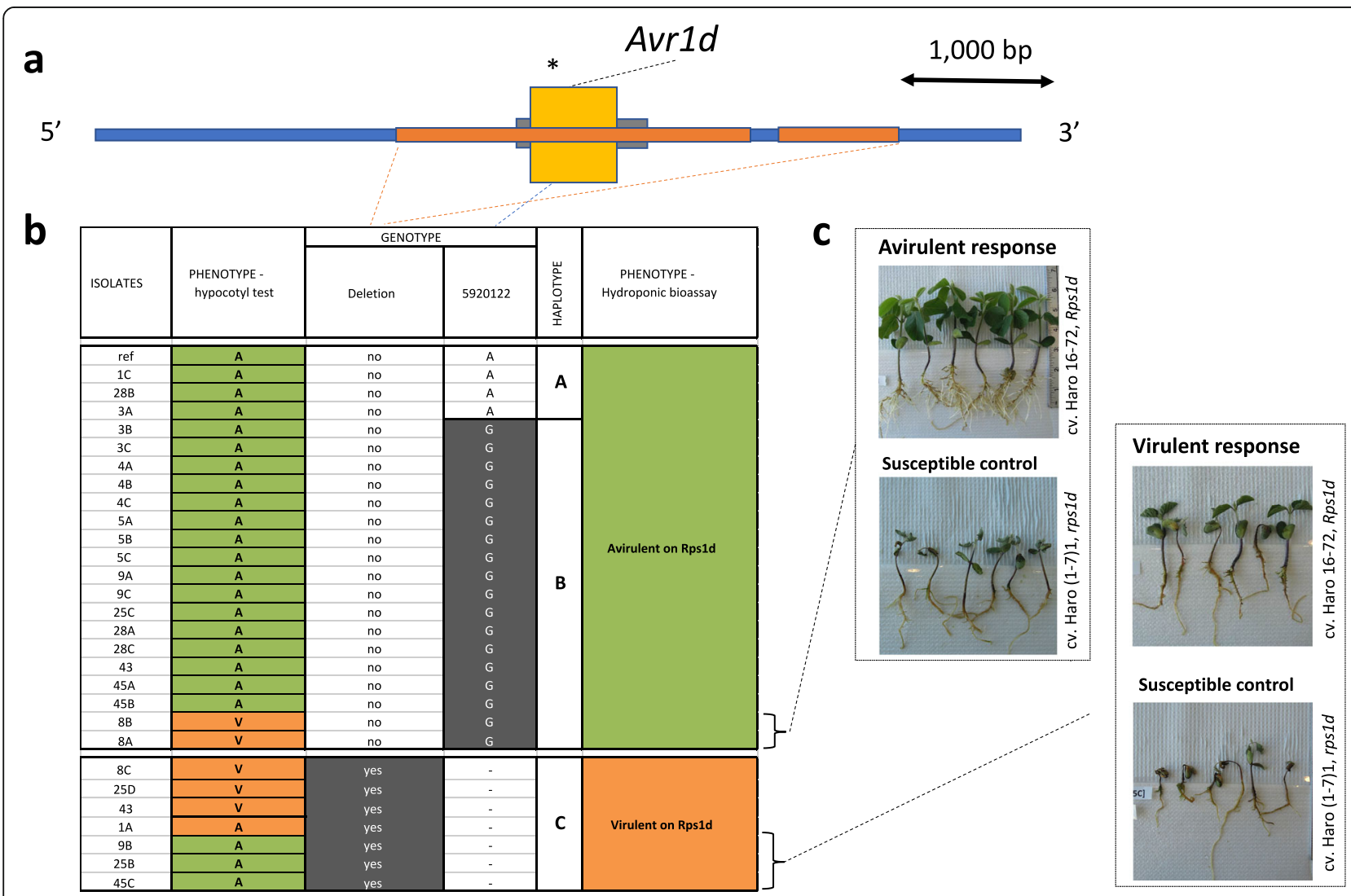

Fig. 6 Structural and nucleotide diversity at the Avr1d locus among 31 isolates of Phytophthora sojae reveal distinct haplotypes associated with virulence phenotypes. a Deletion in the vicinity of the Phytophthora sojae Avrld locus. Yellow box represents exon and gray bars, 5' and 3' UTR. Orange boxes show the position of deletions in virulent isolates. $\mathbf{b}$ Schematic graph of the genotypes based on the deletion. Genotypes in gray background are different from the reference genome (isolate P6497). c Phenotypic response of the outliers (when the phenotype did not match the genotype based on the hypocotyl test) from the hydroponic assay. Responses showed here are representative of all isolates tested. All phenotypic responses of other tested isolates can be found in Additional file 3 


\section{Haplotypes for Avr1k}

No CNVs or deletions were observed for Avr1k (Fig. 7a). Inside the genic region, 16 variants were found: one synonymous variant, 14 missense variants, and one deletion of eight nucleotides causing a frameshift in the ORF and leading to a premature stop codon towards the 3 ' end of the gene (Additional file 1). This latter variant is the only one considered to have a high impact on the functionality of the gene. The three tag variants within the gene (based on LD) formed three distinct haplotypes (Fig. 7b). As observed previously for Avr1b, the first two haplotypes (A and $\mathrm{B}$ ) contained all the isolates avirulent to Rps1k plus four isolates previously phenotyped as virulent to Rps1k with the hypocotyl test. Interestingly, the exact same outliers gave an initial phenotype of virulence with $A v r 1 b$. To verify that the genotype of these outliers had not changed over time, the Avrlk gene region was re-sequenced for these isolates and showed the same mutations as observed by WGS. Haplotype C only contained isolates virulent to Rpslk. Re-phenotyping of the four outliers confirmed their incompatibility with Rps $1 k$ as shown in Fig. 7c. The eight-nucleotide frameshift mutation leading to an early stop codon was found in both haplotypes $\mathrm{B}$ and $\mathrm{C}$, although the former was associated with an avirulent phenotype and the latter with a virulent one.

\section{Haplotypes for Avr3a}

Copy number variation was observed between isolates, ranging from one to four copies; all isolates virulent to $R p s 3 a$ contained one copy of the gene, while all avirulent

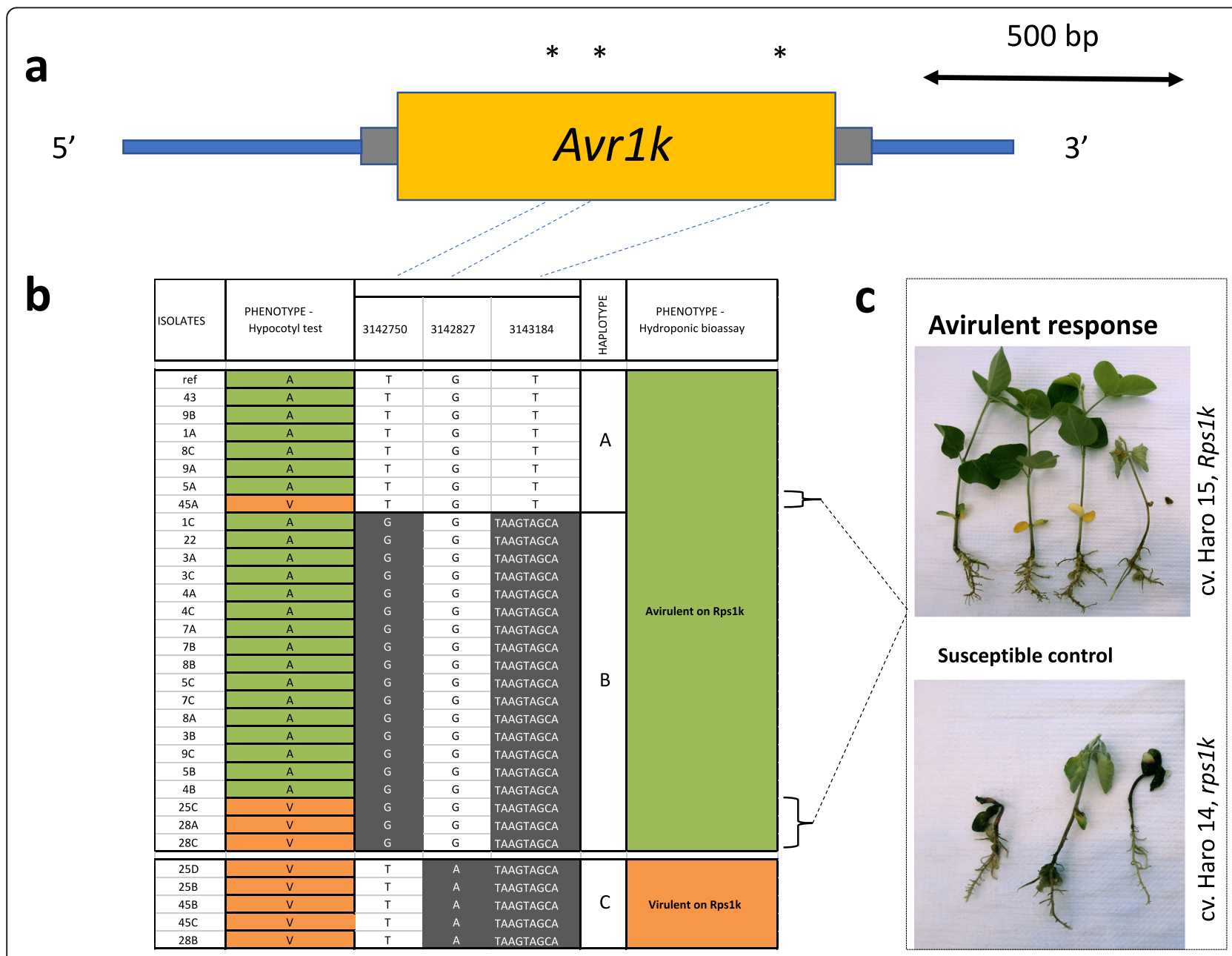

Fig. 7 Nucleotide diversity at the Avrlk locus among 31 isolates of Phytophthora sojae reveal distinct haplotypes associated with virulence phenotypes. a Variants within the coding region of the Phytophthora sojae Avrlk gene. Yellow box represents the coding region of the gene and gray bars, $5^{\prime}$ and $3^{\prime}$ UTR. Asterisks (*) indicate approximate positions of the SNPs and small indel. Those variants are representative of a cluster of variants defining a haplotype. b Schematic graph of the position of the variants for each isolate, regrouped by haplotypes. Variants in gray background are different from the reference genome (isolate P6497). c Phenotypic response of the outliers (when the phenotype did not match the genotype based on the hypocotyl test) from the hydroponic assay. Responses showed here are representative of all isolates tested. All phenotypic responses of other tested isolates can be found in Additional file 3 
isolates had two to four copies (Fig. 8b). Furthermore, we observed 15 variants in the coding region of the Avr $3 a$ gene, including one inframe deletion of six nucleotides and 14 SNPs, of which two were synonymous variants, 11 were missense variants, and one caused the loss of the stop codon (Additional file 1). Only the latter variant is considered to have a high impact on the functionality of the gene. All those variants were homozygous suggesting that for isolates with multiple copies of the Avr3a gene, every copy shares the same allele. Based on the retained tag variant, two distinct haplotypes were observed. Haplotype A was consistently associated with an incompatible interaction with Rps $3 a$ while haplotype $\mathrm{B}$ was associated with a compatible one (Fig. 8b).

\section{Haplotypes for Avr6}

No CNVs or deletions were observed for the Avr6 gene (Fig. 9a). Furthermore, no variants were found within the coding region of Avr6, but five were found in the upstream region of the gene. From these, four were SNPs, and one was a deletion of 15 nucleotides, but none of them were predicted to have a high functional impact (Additional file 1). A visual inspection of these variants revealed two distinct haplotypes, represented by one tag variant in Fig. 9b. All isolates incompatible with Rps6 based on the hypocotyl test were associated with haplotype A, as well as four isolates initially phenotyped as virulent. These four isolates were found to be avirulent to Rps6 via the hydroponic assay (Fig. 9c). Isolates

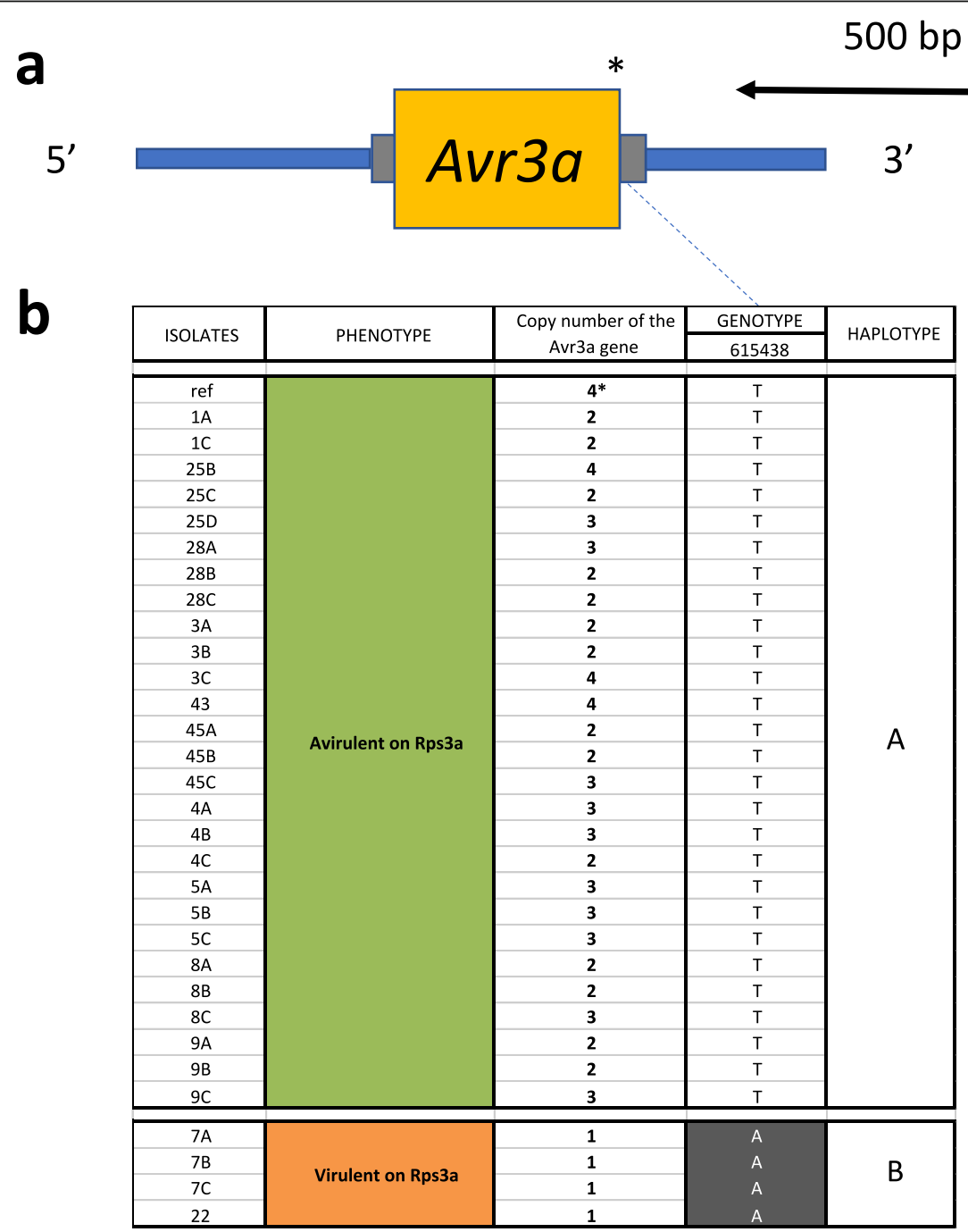

Fig. 8 Structural and nucleotide diversity at the Avr3a locus among 31 isolates of Phytophthora sojae reveal distinct haplotypes associated with virulence phenotypes. a Variants in the coding region of the Phytophthora sojae Avr3a region. Yellow box represents the coding region of the gene and gray bars, 5' and $3^{\prime}$ UTR. Asterisk $\left(^{*}\right)$ indicate approximate positions of the SNPs and small indel. Those variants are representative of a cluster of variants defining a haplotype. $\mathbf{b}$ Schematic graph of the position of the variants for each isolate, regrouped by haplotypes. Variants in gray background are different from the reference genome (isolate P6497). Phenotype results were confirmed by re-testing a number of isolates with the hydroponic assay (Additional file 3). CNV of Avr3a gene for the reference genome (P6497) is based on data from Qutob et al. [13] 


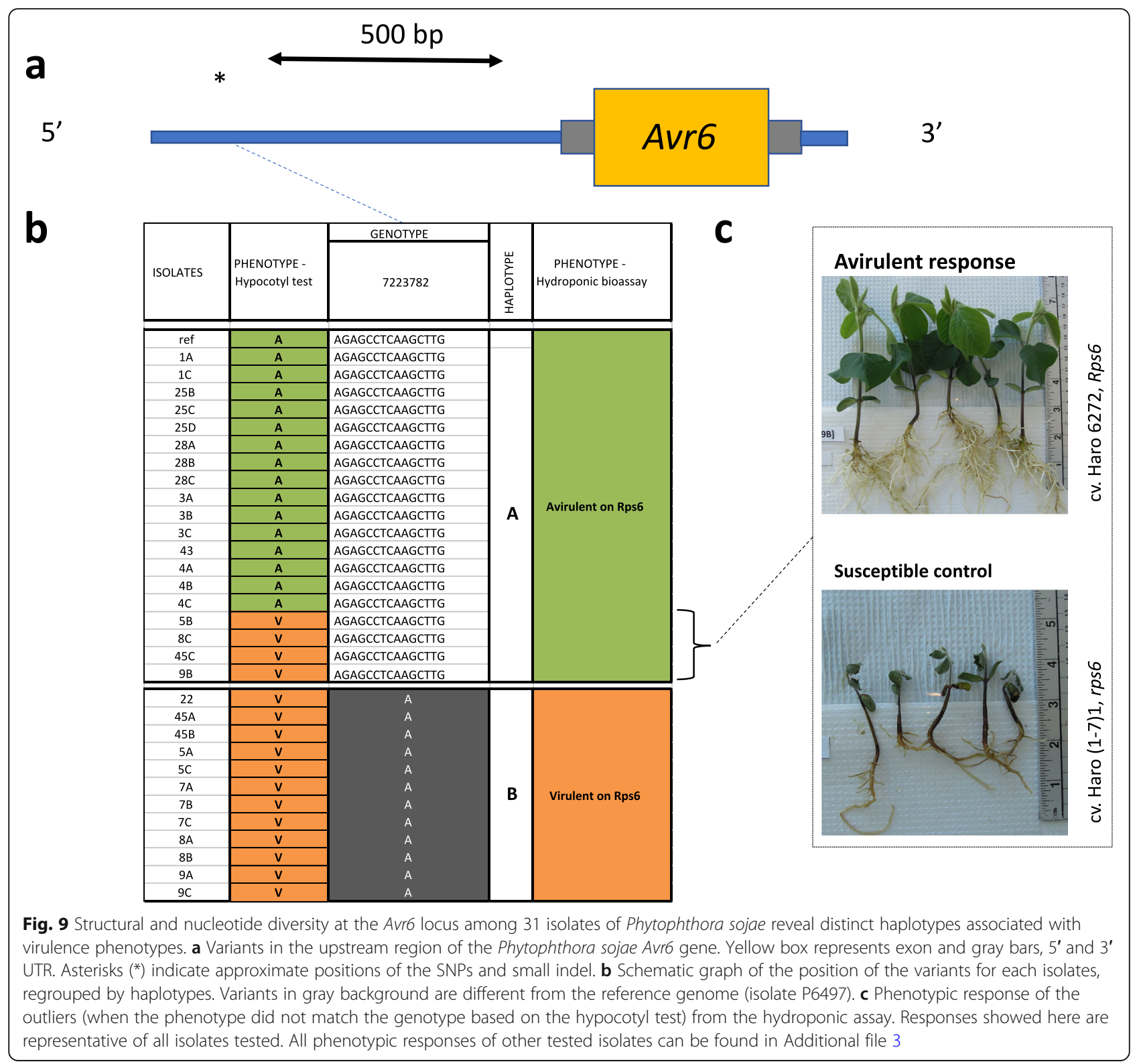

corresponding to haplotype B were consistently associated with a compatible interaction.

\section{Discussion}

This work describes an analysis of the genetic variations of seven $P$. sojae avirulence genes through whole genome sequencing of 31 isolates in an effort to understand and explain their interaction with Rps genes. Through improved re-phenotyping, evaluation of sequence stability over time, expression analysis, and genome-wide sequence comparisons, we define new variants, copy number variations, and potential new factors of virulence of $P$. sojae. We further provide evidence that one haplotype of Avr $1 c$ from the reference genome is likely associated to a different phenotype. Taken together, our results showed that genomic signatures alone accurately predicted 216 of the 217 (99.5\%) phenotype interactions studied, and that those signatures remained stable over time.

In the specific context of the $P$. sojae-soybean interaction, very little attention has been placed on the accuracy and reproducibility of phenotypic procedures when studying the interaction of avirulence and resistance genes. This situation may lead to erroneous inferences with regard to the nature of avirulence genes or the mechanisms explaining gain of virulence, as highlighted in this study. With 31 isolates interacting with seven different Rps genes from soybean, we had a total of 217 interactions to consider that linked the haplotype with the original phenotyping result from the hypocotyl test. The hypocotyl inoculation method has long been used for 
characterizing pathotypes of $P$. sojae isolates but has also encountered some limitations in the past where re-testing gave variable results in terms of virulence profiles, leading to a rate of $10-20 \%$ of false positives or negatives [25]. In our study, 26 out of 217 interactions were initially inconsistent with the observed genotype. We re-phenotyped these using a recently described hydroponic assay [26] and found that 23 out of 26 inconsistent interactions had been incorrectly phenotyped. In addition, we highlighted an incorrect phenotype for Avr1c in the reference isolate P6497. Interestingly, most of the incorrect phenotypes were false positives, namely with Avr1a, Avr1b, Avr1k, and Avr6, indicating that the hypocotyl assay, bypassing the root system, is possibly too stringent. Genetic drift has also been proposed to explain virulence inconsistency of isolates over time [30], but targeted re-sequencing results of all the tested outliers, and of the concerned avr gene region-Avr $1 c-$ for the three remaining outliers (3 out of 26), showed no genetic variation compared to the whole-genome sequences, ruling out the possibility of any change by mutation or contamination within the confines of our experiments (from 2015 to 2017). Considering that of these three outliers, two are potentially explained by genomic features (distant variants putatively affecting an Avr gene in trans), this means that 216 out of 217 interactions were accurately predicted based on genomic signatures. In previous studies, expression polymorphism based on RT-PCR analysis was considered the next step to explain the gain of virulence mechanisms when the haplotype did not match the phenotype. However, downregulation of transcripts failed to explain all situations. For instance, $\mathrm{Na}$ et al. [10] and Shan et al. [31] observed the expression of an avirulence gene for a $P$. sojae isolate with a phenotype of virulence in the case of Avr1a, Avr1c, and Avr1b, respectively. In these cases, it was hypothesized that other effectors or epistatic effects could be responsible for these incongruent results [10]. While we cannot rule out the possibility of these genetic events, our study rather showed that an incorrect phenotype was the main source of discrepancy between the haplotype of Avr genes and the phenotype of $P$. sojae isolates. The use of the hydroponic test by Lebreton et al. [26] allowed rectification of these phenotyping inaccuracies and in particular elimination of false positives.

For most of the avirulence genes we studied, there were many variants representing the diversity of virulence profiles inherent to the $P$. sojae isolates. Many of the Avr effectors we observed had been described by other groups $[3,10-13,31]$. When we compared our data with haplotype analyses from these earlier studies, robust associations could confirm many patterns and resolve discrepancies between both the phenotypes reported previously and the new findings revealed by our analyses.
For Avr1a, we noticed that the complete deletion of the gene was not the sole factor that accounted for virulence of P. sojae to Rps1a. Indeed, while the absence of the gene always conferred virulence, as many as 10 isolates still displayed a phenotype of virulence without a deletion. In an earlier study, Na et al. [10] also observed the presence of Avrla in virulent isolates and attributed this phenomenon to gene silencing. In this work, we were able to identify new SNPs outside the Avrla gene region that discriminated between avirulent and virulent isolates. While the functional impact of these SNPs remains unknown, it will be interesting to determine if they indeed lead to silencing of Avr1a [10,13] or if they affect another gene involved in the virulence to Rps1a. Our data have also further refined the extent of the deletion for Avrla, showing that it can be as large as $10.8 \mathrm{~kb}$, in which case it also encompassed Avrlc. Another interesting observation was the variation in the number of copies of Avrla among the isolates. In a previous study, Qutob et al. [13] identified a tandem array of two identical copies of Avr1a and established a link between virulence and deletion of both copies, although a few isolates were virulent in spite of the presence of the gene. Within the population of 31 isolates studied, we found that the copy number could be as high as three in more than $50 \%$ of the isolates and included isolates displaying a phenotype of virulence. However, in the latter cases, we identified haplotypes associated with this phenotype of virulence to Rps1a.

With respect to Avr1b, our results identified three distinct haplotypes among the 31 isolates. More importantly, all our tested isolates with haplotype A had an incompatible interaction with differentials carrying $R p s 1 b$ or Rps1k. This contrasts with data for isolate P6497, which possesses the same haplotype, but has been reported as virulent to Rps $1 b$ (and avirulent to Rps1k), based on the hypocotyl or infiltration tests [31], a phenotype confirmed in this study by the hydroponic assay. Given the possible different genetic background between our isolates and isolate P6497, we could also hypothesize that epistasic interactions leading to differences in gene expression as observed by Shan et al. [31] might be responsible for the different virulence profile of P6497. Table 1 presents a comparative analysis of the phenotypes attributed to the haplotypes found in Shan et al. [31] compared to our data. Because Avrlb and Avr1k are tightly linked [8], and Avr1b can also determine virulence to Rps1k [3], the table presents the phenotype to Rps $1 b$ and Rps $1 k$ linked to the haplotype. Haplotype I from Shan et al. [31] comprised isolates with different virulence profiles (virulent/avirulent to $R p s 1 b$ and $R p s 1 k$ ). In our case, all isolates with haplotype A, corresponding to haplotype I, were avirulent to Rps $1 b$ and Rps1k following re-phenotyping except for isolate 
Table 1 Comparison of haplotypes/phenotypes of 31 isolates of Phytophthora sojae evaluated in this study compared to data from Shan et al. [31]

\begin{tabular}{|c|c|c|c|c|c|}
\hline \multicolumn{3}{|l|}{ This study } & \multicolumn{3}{|c|}{ Shan et al., 2004} \\
\hline \multirow[t]{2}{*}{ Haplotype } & \multicolumn{2}{|l|}{ Virulence } & \multirow[t]{2}{*}{ Haplotype } & \multicolumn{2}{|c|}{ Virulence } \\
\hline & Rpsib & Rpsik & & Rpsib & Rpsik \\
\hline $\bar{A}$ & $A(6 / 6)^{a}$ & $A(6 / 6)$ & 1 & $V(3 / 4)$ & $A(3 / 4)$ \\
\hline B & A (20/20) & A $(20 / 20)$ & IV & $A(2 / 2)$ & A $(2 / 2)$ \\
\hline C & $V(5 / 5)$ & $\vee(5 / 5)$ & $\|$ & $V(1 / 1)$ & $V(1 / 1)$ \\
\hline- & - & - & III & $V(1 / 1)$ & $A(1 / 1)$ \\
\hline
\end{tabular}

$A$ avirulent, $V$ virulent

${ }^{\text {a }}$ Ratio in parenthesis indicates number of isolates with the corresponding phenotypes over the number of isolates within the given haplotype

P6497. Incidentally, Shan et al. (2004) also observed a pattern of virulence with P6497 as well as an avirulent isolate with the same haplotype and attributed the differences to a higher expression of $A v r 1 b$ in the latter isolate, stimulated or stabilized by another elusive gene called Avr1b-2. The other two haplotypes, B and C, revealed from our data correspond to haplotype II and IV from the previous study, and the phenotypes associated with them are identical. The fourth haplotype described by Shan et al. [31] and missing from our isolates, haplotype III, was associated with a rare pattern of virulence to $R p s 1 b$ and avirulence to Rps $1 \mathrm{k}$.

A surprising feature for Avrlk was the presence of a frameshift mutation leading to an early stop codon in both haplotypes $\mathrm{B}$ and $\mathrm{C}$, similar to the one reported by Song et al. [3]. If the truncation of the Avr1k protein makes it unrecognizable by Rps $1 k$, this mutation should lead to a phenotype of virulence although isolates with haplotype $\mathrm{B}$ were avirulent. This phenomenon can be explained by the fact that the latter isolates share the same haplotype for $A v r 1 b$, which is seemingly recognized by Rps $1 k$. Concerning the $A v r 1 b / A v r 1 k$ interaction, it would be interesting to further study isolates that only show virulence to $R p s 1 b$ or $R p s 1 k$ to see if this pattern has evolved new or unusual haplotypes.

For three of the 31 isolates tested, deletion of Avr1c led to an expected virulence to plants carrying Rps1c. However, as with $A v r 1 b$, our data for $A v r 1 c$ gave contrasting results of virulence when phenotyping the isolates with the haplotype of the reference genome (haplotype A). Re-phenotyping of the reference isolate confirmed a reaction of virulence in association with haplotype A. This suggests that Avr1c, as previously described, does not lead to a reaction of incompatibility with $R p s 1 c$, a situation that may explain why the efficacy of Rps1c has been described as unstable in the field [32]. Incidentally, $\mathrm{Na}$ et al. [10], who first identified $A v r 1 c$, also observed some discrepancy when phenotyping $P$. sojae isolates containing $A v r 1 c$, a situation they attributed mostly to gene silencing. On the basis of that suggestion, we further analyzed those isolates. Of the three remaining outliers following the phenotyping with the hydroponic assay, all isolates were associated with Avr1c and were virulent against soybean lines carrying Rps1c while associated with a haplotype that should confer an avirulent reaction. Expression analysis showed that Avr1c was significantly less expressed in these outliers compared to avirulent isolates presenting the same haplotype, which would explain the phenotypes observed. From a functional point of view, we hypothesized that this lower expression could find its origin in genomic variations. Incidentally, genome-wide sequence comparison revealed the deletion of a gene from the Sin3 family for one of the outliers, and deletion of the putative avirulence gene $A v h 220$ for another. These results offer a potential explanation for the transient expression of the avirulence gene and propose the implication of new genes in the virulence of P. sojae to Rps1c. These findings were only made possible because of the extensive whole genome sequencing analyses. Further investigations are needed to confirm that these two genes are interacting with Rps1c, but their nature offers a priori evidence of their implication in virulence. Indeed, the protein encoded by the deleted gene from the Sin3 family is recognized as a regulator of transcription [33]. Computational prediction for $A v h 220$, the second gene found to be deleted in one isolate, suggests it is a putative RXLR effector with a potential role in virulence. The mechanism by which the sole remaining outlier, isolate $45 \mathrm{~B}$, succeeds in escaping Rps $1 c$ is still unclear. The many unique mutations found for this isolate do not seem to be linked to any factors related to virulence, but the possibility that this can lead to an epistatic interaction of one or many genes with the Avr1c gene cannot be completely dismissed. Epigenetic mechanisms might also be involved in the gain of virulence on Rps1c plants for this isolate. Another interesting aspect of Avrlc was the discovery a new allele (haplotype D) that shared many similarities with Avr1a sequences [10]. It is well known that Avrla and $A v r 1 c$ are closely related but reads from this allele were distinct from those that aligned against Avrla, which would rule out the possibility of misalignment. Considering that Avr1a and Avr1c are often subjected to deletion, one could speculate that they are in the presence of DNA repair although proof for this process is lacking in $P$. sojae. Finally, a rare case of heterozygous variants was observed with two isolates (haplotype $\mathrm{C}$ ). Because this heterozygosity is not encountered all across the gene region for those isolates, we excluded the presence of two different alleles as a result of sexual segregation but attributed it instead to the observed duplication of the Avr1c gene for those two isolates, resulting in presence of reads from both copies of Avr1c on the same locus following alignment on the reference genome. 
A complete deletion of the Avrld gene was also observed in some isolates but, unlike the case of Avrla, a constant phenotype of virulence was associated with this deletion. An absence of coverage along a 2.2-kb segment with another upstream deletion of $0.8 \mathrm{~kb}$, separated by a segment of $177 \mathrm{bp}$, including the Avrld gene, was indeed revealed through our data. Previously, a deletion/virulence link for Avrld was also reported by $\mathrm{Na}$ et al. [34] with the distinction that the latter group observed an absence of read coverage along a shorter segment of $1.5 \mathrm{~kb}$ in the isolates studied. Over time, it will be interesting to determine if the difference can be explained by an evolving zone of deletion or simply a different variant.

The haplotype analysis for $A v r 3 a$ has revealed two distinct alleles, and a distinctive phenotyping response separating these two haplotypes, with no outlier. In addition to the discriminant haplotypes, all virulent isolates contained only one copy of the gene while the avirulent isolates contained between two and four copies, in contrast to previous results that reported exclusively four copies in avirulent isolates [13]. The haplotypes were similar to the ones described by Dong et al. [11]. In contrast, two SNPs reported in the earlier study did not appear in any of the isolates tested, although they do not affect the haplotype sequences.

In the case of Avr6, two distinct haplotypes emerged clearly delineating the interactions of compatibility and incompatibility once the isolates were re-phenotyped. Because of our extensive coverage, we were able report a unique SNPs and a deletion of $15 \mathrm{bp}$ further upstream that represents a clear discriminant zone between virulent and avirulent isolates. SNPs closest to the gene were also reported in P. sojae isolates by Dou et al. [12].

\section{Conclusions}

In conclusion, we took advantage of a new phenotyping procedure and WGS of $31 P$. sojae isolates representative of the genetic diversity found in Canadian fields to conduct an exhaustive association analysis of phenotype and genotype for a total of 217 interactions. Our results identified new variants and new properties of some Avr effectors and refined the phenotypes associated with each variant to show that genomic signatures provided a near perfect prediction of phenotypes. We further suggest that the virulence model previously described for $A v r 1 c$ should be reassessed.

\section{Methods}

\section{Plant material and Phytophthora sojae isolates}

A total of 31 isolates of $P$. sojae were selected on the basis of their diverse pathotypes for seven avirulence genes (1a, 1b, 1c, 1d, 1k, 3a and 6) and their prevalence (80\%) among the races found in a collection of 275 isolates sampled across Ontario (Canada) between 2010 and 2012 and retrieved from Xue et al. [29]. Whenever possible, three isolates of the same race were used for analysis (Table 2). The reference strain P6497 was obtained from Dr. Mark Gijzen (Agriculture and Agri-food Canada, London, Ontario). Each of the 31 isolates was previously characterized for the presence of Avr genes using the hypocotyl wound-inoculation technique [29] where a set of eight differential soybean lines were used, each containing a single resistance Rps gene (Rps1a, Rps1b, Rps1c, Rps1d, Rps1k, Rps3a, Rps6, and Rps7), and "Williams" (rps) as a universal susceptible check.

\section{DNA extraction and sequencing}

DNA was extracted for each of the 31 isolates using the E.Z.N.A. Plant DNA Kit (Omega Bio-Tek Inc., Norcross, GA, USA). The DNA quantity and quality was assessed using a NanoDrop ND-1000 spectrophotometer (NanoDrop technologies). Each sample was normalized to $10 \mathrm{ng} / \mu \mathrm{L}$ for sequencing library construction using the NEBNext Ultra II DNA Library Prep Kit for Illumina (New England BioLabs Inc., Ipswich, MA, USA). Library quality was determined using the Agilent 2100 Bioanalyzer (Agilent Technologies). An average fragment size of approximately $650 \mathrm{bp}$ was observed among all 31 individual samples. Paired-end, 250-bp sequencing was performed on an Illumina HiSeq 2500 (CHU, Québec, Canada).

\section{Reads alignment to the reference genome}

Quality of the reads obtained from sequencing was checked using FastQC (Babraham Institute, Cambridge, UK). Reads were processed using Trimmomatic [35] to remove adapter sequences and bases with a Phred score below 20 (using the Phred +33 quality score). Trimmed reads were aligned against the $P$. sojae reference genome

Table 2 Races and associated pathotypes of Phytophthora sojae isolates characterized in this study, as determined by hypocotyl wounding inoculation [29]

\begin{tabular}{llll}
\hline Race & Pathotype & Number of isolates & Isolates IDs \\
\hline 1 & 7 & 2 & $1 \mathrm{~A}, 1 \mathrm{C}$ \\
3 & $1 \mathrm{a}, 7$ & 3 & $3 \mathrm{~A}, 3 \mathrm{~B}, 3 \mathrm{C}$ \\
4 & $1 \mathrm{a}, 1 \mathrm{c}, 7$ & 3 & $4 \mathrm{~A}, 4 \mathrm{~B}, 4 \mathrm{C}$ \\
5 & $1 \mathrm{a}, 1 \mathrm{c}, 6,7$ & 3 & $5 \mathrm{~A}, 5 \mathrm{~B}, 5 \mathrm{C}$ \\
7 & $1 \mathrm{a}, 3 \mathrm{a}, 6,7$ & 3 & $7 \mathrm{~A}, 7 \mathrm{~B}, 7 \mathrm{C}$ \\
8 & $1 \mathrm{a}, 1 \mathrm{~d}, 6,7$ & 3 & $8 \mathrm{~A}, 8 \mathrm{~B}, 8 \mathrm{C}$ \\
9 & $1 \mathrm{a}, 6,7$ & 3 & $9 \mathrm{~A}, 9 \mathrm{~B}, 9 \mathrm{C}$ \\
22 & $1 \mathrm{a}, 1 \mathrm{c}, 3 \mathrm{a}, 6,7$ & 1 & 22 \\
25 & $1 \mathrm{a}, 1 \mathrm{~b}, 1 \mathrm{c}, 1 \mathrm{k}, 7$ & 3 & $25 \mathrm{~B}, 25 \mathrm{C}$ \\
$25+1 \mathrm{~d}$ & $1 \mathrm{a}, 1 \mathrm{~b}, 1 \mathrm{c}, 1 \mathrm{~d}, 1 \mathrm{k}, 7$ & & $25 \mathrm{D}$ \\
28 & $1 \mathrm{a}, 1 \mathrm{~b}, 1 \mathrm{k}, 7$ & 3 & $28 \mathrm{~A}, 28 \mathrm{~B}, 28 \mathrm{C}$ \\
43 & $1 \mathrm{a}, 1 \mathrm{c}, 1 \mathrm{~d}, 7$ & 1 & 43 \\
45 & $1 \mathrm{a}, 1 \mathrm{~b}, 1 \mathrm{c}, 1 \mathrm{k}, 6,7$ & 3 & $45 \mathrm{~A}, 45 \mathrm{~B}, 45 \mathrm{C}$ \\
\hline
\end{tabular}


V3.0 [27] using the Burrows-Wheeler Transform Alignment (BWA) software package v0.7.13 [36].

\section{Phylogenetic analysis}

Phylogenetic inference of the isolates was made based on variant data obtained from the whole genome resequencing and a subset of variants identified within the region of seven Avr genes (1a, 1b, 1c, 1d, 1k, 3a, 6). The phylogenetic tree was developed by using a neighbor-joining method in Tassel software [37] and then visualized using MEGA 6.0 software tool [38]. Bootstrapping (500 replicates) was used to calculate the percentage of replicate trees in which the associated taxa were clustered together.

\section{Haplotype analysis}

Haplotype analysis was done using a systematic approach. For every Avr gene studied, we began by searching for evidence of structural variation, namely presence/absence polymorphisms and copy number variation. We then examined nucleotide variation (SNPs or indels) within the genic regions that could be expected to lead to a loss of activity or that defined a specific haplotype that could be associated with the virulence phenotype. When further analysis was needed to find discriminant haplotypes, we also surveyed mutations in the vicinity of the gene. Once derived haplotypes were established, if discrepancies occurred between the observed genotype and phenotype for some isolates, virulence testing was performed using a hydroponic assay (see below). If the phenotype was still incongruent with the genotype for these isolates, as with $A v r 1 c$, we measured Avr gene expression to see if changes in transcript abundance could explain a gain of virulence. In parallel, targeted re-sequencing of the gene under investigation was done to check for mutation or contamination in the isolates that could have occurred in the time elapsed between DNA isolation for WGS and the ensuing virulence test. Targeted re-sequencing was also carried out for $A v r 1 b$ and $A v r 1 k$ in isolates and in the reference strain P6497 that had a discordance between the genotype and the phenotype.

\section{Presence/absence polymorphisms and copy number variation}

To detect loss of avirulence genes in some isolates from the reference genome (presence/absence polymorphisms), we calculated the breadth of coverage for each gene, corresponding to the percentage of nucleotides with at least one mapped read ( $1 \times$ coverage), as per Raffaele et al. [39]. If the value of the breadth of coverage was below $80 \%$, the gene was considered to be absent. For detection of copy number variation (CNV), we compared the average depth of coverage for each locus in every isolate and normalized the counts using the mean coverage of the genic region in every isolate.

\section{Variant detection}

Variant calling was done using the Genome Analysis Toolkit (GATK) [40], a variant calling pipeline based on GATK's best practices. The resulting raw vcf file was quality filtered using the vcfR package [41]. For haplotype visualization, a simple visual inspection was sufficient in most cases, but a custom script developed at Université Laval was used in other cases, based on a gene-centric haplotyping process that aims to select only markers in the vicinity of a gene that are found to be in strong linkage disequilibrium (LD).

\section{Virulence screening using the hydroponic assay}

Whenever an isolate or P6497 had a phenotype predicted by the hypocotyl assay [29] discordant from the other isolates within a given haplotype, this isolate was re-phenotyped using a hydroponic assay, in which zoospores are inoculated directly into the hydroponic nutrient solution [26]. For this purpose, the isolate was tested against the appropriate differential line with three to six plants depending on the number of outliers to be tested within a given haplotype and the hydroponic system capacity for every replicate together with a susceptible control cultivar not carrying the appropriate Rps gene, a resistant control cultivar and a number of control isolates (see Additional file 3). Phenotypic responses for resistance or susceptibility were recorded at 14 days post-inoculation.

\section{Expression analysis}

Total RNA was extracted from 7-day-old P. sojae-infected soybean roots using the Trizol reagent followed by purification using the Qiagen RNeasy Mini kit (Valencia, CA, USA). The RNA samples were treated with DNase I enzyme to remove any contaminating DNA. A total of $3 \mu \mathrm{g}$ RNA from each sample were used to synthesize single-stranded cDNA using oligo-dT primed reverse transcription and Superscript II reverse transcriptase (Invitrogen $^{\text {тs }}$, Carlsbad, CA, USA) following the manufacturer's protocol. Primers for the quantitative reverse transcription PCR (qPCR) analysis were designed using PrimerQuest tool and the intercalating dyes design option (Additional file 4; Coralville, IA, USA). Four biological replications were used for the expression analysis. Expression analysis was carried out for Avr genes in both avirulent and virulent isolates using the $\mathrm{iQ}^{\mathrm{TM}} \mathrm{SYBR}^{\circ}$ Green Supermix (Bio-Rad, Hercules, CA, USA) and a MIC qPCR thermocycler machine (Bio Molecular Systems, Upper Coomera, Queensland, Australia). The PCR profile consisted of an initial activation of $95{ }^{\circ} \mathrm{C}$ for $3 \mathrm{~min}$, followed by 40 cycles of $95{ }^{\circ} \mathrm{C}$ for $15 \mathrm{~s}$ and $60{ }^{\circ} \mathrm{C}$ for $45 \mathrm{~s}$. After cycling, dissociation curve analysis (with an initial hold of $95^{\circ} \mathrm{C}$ for $10 \mathrm{~s}$ followed by a subsequent temperature increase from 55 to $95{ }^{\circ} \mathrm{C}$ at $0.5{ }^{\circ} \mathrm{C} / \mathrm{s}$ ) was 
performed to confirm the absence of nonspecific amplification. Actin was used as a constitutively expressed reference transcript. Relative quantification analysis was performed using the MIC-qPCR software which uses the LinRegPCR method developed by Ruijter et al. [42] and the Relative Expression Software Tool (REST) for statistical significance [43].

\section{Confirmation of haplotype variation using sanger sequencing}

The isolates were freshly grown in V8 agar media for 7 days under controlled conditions followed by DNA extraction. Regions spanning the Avr genes were amplified using specific sets of primers (Additional file 3). The PCR profile was initial denaturation at $98^{\circ} \mathrm{C}$ for $30 \mathrm{~s}$ followed by 35 cycles of denaturation at $98^{\circ} \mathrm{C}$ for $10 \mathrm{~s}$, annealing at $60^{\circ} \mathrm{C}$ for $30 \mathrm{~s}$ and extension at $72^{\circ} \mathrm{C}$ for $2 \mathrm{~min}$, and the final extension at $72^{\circ} \mathrm{C}$ for $10 \mathrm{~min}$. The PCR products were purified using the QIAquick PCR purification kit (Qiagen, Valencia, CA, USA) followed by sequencing on an Applied Biosystems sequencer (ABI 3730xl DNA Analyze) located at the CHU, Quebec, Canada. The sequencing results were analyzed using the SeqMan program implemented in the DNASTAR Lasergene software (Madison, WI, USA).

\section{Additional files}

Additional file 1: All variants (SNPs and indels) found among 31 isolate of Phytophthora sojae for seven Avr genes. (XLSX $54 \mathrm{~kb}$ )

Additional file 2: Sequence alignment of $\operatorname{Sin} 3$ transcription factor showing deletion in 5C isolate. (XLSX $284 \mathrm{~kb}$ )

Additional file 3: Phenotypic responses of all isolates tested with the hydroponic assay. (PDF $40 \mathrm{~kb}$ )

Additional file 4: Primer sequences used for real time PCR and Sanger sequencing. (XLSX $16 \mathrm{~kb}$ )

Additional file 5: Individual values for relative expression of the Phytophthora sojae Avrlc gene measured by real-time quantitative PCR in avirulent and virulent isolates. (PDF $48 \mathrm{~kb}$ )

\section{Abbreviations}

Avr: Avirulence; bp: Base pairs; CNV: Copy number variation; DLs: Differential lines; LD: Linkage disequilibrium; NILs: Near-isogenic lines; NLR: Nucleotidebinding domain and leucine-rich repeat region; ORF: Open-reading frame; Rps: Resistance to $P$. sojae genes; SNPs: Single nucleotide polymorphisms; WGS: Whole genome sequencing

\section{Acknowledgements}

We would like to thank Brian Boyle and Jérôme Laroche from the Plateforme de Bio-Informatique of IBIS-Université Laval, Aurélie Tardivel from Université Laval, and Javier Tabima and Shankar Shakya from Horticultural Crops Research Laboratory, USDA-ARS, Oregon State University for assistance with bioinformatic analyses. We thank Dr. Mark Gijzen (AAFC, London, Ontario) for providing isolate P6497.

\section{Funding}

We would like to thank the following partners for their financial support: Genome Canada, Génome Québec, Ministère de l'Économie, Innovation et Exportation du Québec, Western Grains Research Foundation, Canadian Field Crop Research Alliance, Institut de Biologie Intégrative et des Systèmes (IBIS-
ULaval), Centre de recherche sur les grain (CEROM), Agriculture and Agri-Food Canada, the University of Guelph, Semences Prograin, Syngenta, Sevita Genetics, la Coop Fédérée, Producteurs de grains du Québec, Grain Farmers of Ontario, Manitoba Pulse and Soybean Growers, Saskatchewan Pulse Growers, Réseau d'avertissements phytosanitaires and Empresa Brasileira de Pesquisa Agropecuária (EMBRAPA). This work was further supported by grants from the Natural Sciences and Engineering Research Council of Canada and the Canada Research Chairs Program to RRB. The financing supported totally or in part the salaries of the students and researchers involved in the project and the materials. The authors declare that the research was conducted in the absence of any commercial or financial relationships that could be construed as a potential conflict of interest.

\section{Availability of data and materials}

The datasets generated and analyzed during the current study are available in the NCBI SRA repository, under the bioproject PRJNA434589.

\section{Authors' contributions}

AX and GM isolated, characterized and provided the isolates for the study. GAL performed DNA extraction, sequence library construction, bioinformatics analyses, interpretation of data and participated in writing of the manuscript. HS participated in bioinformatic analyses, expression analysis, re-sequencing, and interpretation of data and participated in writing of the manuscript. CL contributed to sequence library construction, bioinformatics analyses, and maintenance of $P$. sojae collection. AL performed virulence screening of isolates. BJK and NJG contributed to bioinformatics analyses. FB and RRB conceived the study and participated in the interpretation of data and writing of the manuscript. All authors have read and approved the final manuscript.

\section{Ethics approval and consent to participate}

Not applicable.

\section{Consent for publication}

Not applicable.

\section{Competing interests}

The authors declare that they have no competing interests.

\section{Publisher's Note}

Springer Nature remains neutral with regard to jurisdictional claims in published maps and institutional affiliations.

\section{Author details}

'Département de Phytologie, Université Laval, Québec, QC, Canada. ${ }^{2}$ Agriculture and Agri-Food Canada, Harrow, ON, Canada. ${ }^{3}$ Agriculture and Agri-Food Canada, Ontario, ON, Canada. ${ }^{4}$ Horticultural Crops Research Laboratory, USDA Agricultural Research Service, Corvallis, OR, USA.

Received: 11 April 2018 Accepted: 19 July 2018

Published online: 26 July 2018

\section{References}

1. Kamoun S, Furzer O, Jones JDG, Judelson HS, Ali GS, Dalio RJD, et al. The top 10 oomycete pathogens in molecular plant pathology. Mol Plant Pathol. 2015;16:413-34.

2. Sahoo DK, Abeysekara NS, Cianzio SR. A novel Phytophthora sojae resistance Rps12 gene mapped to a genomic region that contains several Rps genes. PLoS One. 2017:12:e0169950.

3. Song T, Kale SD, Arredondo FD, Shen D, Su L, Liu L, et al. Two RxLR Avirulence genes in Phytophthora sojae determine soybean Rps 1 kmediated disease resistance. Mol Plant-Microbe Interact. 2013;26:711-20

4. Tyler BM, Gijzen M. The Phytophthora sojae genome sequence: foundation for a revolution. In: Dean RA, Lichens-Park A, Kole C, editors. Genomics of plant-associated fungi and oomycetes: dicot pathogens. Berlin, Heidelberg: Springer; 2014. p. 133-57.

5. Gijzen M, Förster H, Coffey MD, Tyler B. Cosegregation of Avr4 and Avr6 in Phytophthora sojae. Can J Bot. 1996;74:800-2.

6. May KJ, Whisson SC, Zwart RS, Searle IR, Irwin JAG, MacLean DJ, et al. Inheritance and mapping of 11 avirulence genes in Phytophthora sojae. Fungal Genet Biol. 2002;37:1-12. 
7. MacGregor T, Bhattacharyya M, Tyler B, Bhat R, Schmitthenner AF, Gijzen M. Genetic and physical mapping of Avr1a in Phytophthora sojae. Genetics. 2002;160:949-59.

8. Whisson SC. Phytophthora sojae avirulence genes, RAPD, and RFLP markers used to construct a detailed genetic linkage map. Mol Plant-Microbe Interact. 1995:8:988.

9. Tyler BM, Förster H, Coffey MD. Inheritance of avirulence factors and restriction fragment length polymorphism markers in outcrosses of the oomycete Phytophthora sojae. Mol Plant-Microbe Interact. 1995;8:515-23.

10. Na R, Yu D, Chapman BP, Zhang Y, Kuflu K, Austin R, et al. Genome resequencing and functional analysis places the Phytophthora sojae avirulence genes Avr1c and Avr1a in a tandem repeat at a single locus. PLoS One. 2014;9:e89738

11. Dong S, Yu D, Cui L, Qutob D, Tedman-Jones J, Kale SD, et al. Sequence variants of the Phytophthora sojae RXLR effector Avr3a/5 are differentially recognized by Rps 3a and Rps 5 in soybean. PLoS One. 2011;6:e20172.

12. Dou D, Kale SD, Liu T, Tang Q, Wang X, Arredondo FD, et al. Different domains of Phytophthora sojae effector Avr4/6 are recognized by soybean resistance genes Rps4 and Rps6. Mol Plant-Microbe Interact. 2010;23:425-35.

13. Qutob D, Tedman-Jones J, Dong S, Kuflu K, Pham H, Wang Y, et al. Copy number variation and transcriptional polymorphisms of Phytophthora sojae RXLR effector genes Avr1a and Avr3a. PLoS One. 2009;4:e5066.

14. Dorrance AE. Management of Phytophthora sojae of soybean: a review and future perspectives. Can J Plant Pathol. 2018;40:210-9.

15. Kadam S, Vuong TD, Qiu D, Meinhardt CG, Song L, Deshmukh R, et al. Genomic-assisted phylogenetic analysis and marker development for next generation soybean cyst nematode resistance breeding. Plant Sci. 2016;242:342-50.

16. Verta JP, Landry CR, MacKay J. Dissection of expression-quantitative trait locus and allele specificity using a haploid/diploid plant system —insights into compensatory evolution of transcriptional regulation within populations. New Phytol. 2016;211:159-71.

17. Zeng P, Zhou X, Huang S. Prediction of gene expression with cis-SNPs using mixed models and regularization methods. BMC Genomics. 2017;18:368.

18. Haas JH, Buzzell Rl. New races 5 and 6 of Phytophthora megasperma var. sojae and differential reactions of soybean cultivars for races 1 to 6 . Phytopathology. 1976;66:1361-2.

19. Kilen TC, Hartwig EE, Keeling BL. Inheritance of a second major gene for resistance to Phytophthora rot in soybeans 1. Crop Sci. 1974;14:260-2.

20. Ward EW, Lazarovits G, Unwin CH, Buzzell RI. Hypocotyl reactions and glyceollin in soybeans inoculated with zoospores of Phytophthora megasperma var. sojae. Phytopathology. 1979;69:1-955.

21. Morrison RH, Thorne JC. Inoculation of detached cotyledons for screening soybeans against two races of Phytophthora Megasperma Var. Sojae 1. Crop Sci. 1978;18:1089-91.

22. Wagner RE, Wilkinson HWP. An aeroponics system for investigating disease development on soybean taproots infected with Phytophthora sojae. Plant Dis. 1992;76:610-4.

23. Pazdernik DL, Hartman GL, Huang YH, Hymowitz T. A greenhouse technique for assessing Phytophthora root rot resistance in Glycine max and G. Soja. Plant Dis. 2007;81:1112-4.

24. Dorrance $A E$, Jia $H$, Abney TS. Evaluation of soybean differentials for their interaction with Phytophthora sojae. PHP Plant Health Prog. 2004; https:// doi.org/10.1094/PHP-2004-0309-01-RS

25. Schmitthenner AF, Hobe M, Bhat RG. Phytophthora sojae races in Ohio over a 10-year interval. Plant Dis. 1994:78:269-76.

26. Lebreton A, Labbe C, de Ronne M, Xue AG, Marchand G, Bélanger RR. Development of a simple hydroponic assay to study vertical and horizontal resistance of soybean and pathotypes of Phytophthora sojae. Plant Dis. 2018;102:114-23.

27. Tyler BM, Tripathy S, Zhang $X$, Dehal $P$, Jiang RHY, Aerts $A$, et al. Phytophthora genome sequences uncover evolutionary origins and mechanisms of pathogenesis. Science. 2006;313:1261-6.

28. Cingolani P, Platts A, Wang LL, Coon M, Nguyen T, Wang L, Land SJ, Lu X, Ruden DM. A program for annotating and predicting the effects of single nucleotide polymorphisms, SnpEff: SNPs in the genome of Drosophila melanogaster strain w1118; iso-2; iso-3. Fly. 2012;6:80-92.

29. Xue AG, Marchand G, Chen Y, Zhang S, Cober ER, Tenuta A. Races of Phytophthora sojae in Ontario, Canada, 2010-2012. Can J Plant Pathol. 2015; 37:376-83.
30. Dorrance A. Phytophthora sojae on soybean. In: Lamour K, editor. Phytophthora: a global perspective. Wallingford, Oxfordshire, UK: CABI; 2013. p. $79-86$.

31. Shan W, Cao M, Leung D, Tyler BM. The Avr1b locus of Phytophthora sojae encodes an elicitor and a regulator required for Avirulence on soybean plants carrying resistance gene Rps1 b. Mol Plant-Microbe Interact. 2004;17: 394-403.

32. Malvick DK, Grunden E. Traits of soybean-infecting Phytophthora populations from Illinois agricultural fields. Plant Dis. 2004;88:1139-45.

33. Silverstein RA, Ekwall K. Sin3: a flexible regulator of global gene expression and genome stability. Curr Genet. 2004:47:1-17.

34. Na R, Yu D, Qutob D, Zhao J, Gijzen M. Deletion of the Phytophthora sojae avirulence gene Avr1d causes gain of virulence on Rps1d. Mol PlantMicrobe Interact. 2013;26:969-76.

35. Bolger AM, Lohse M, Usadel B. Trimmomatic: a flexible trimmer for Illumina sequence data. Bioinformatics. 2014;30:2114-20.

36. Li H, Durbin R. Fast and accurate short read alignment with burrowswheeler transform. Bioinformatics. 2009:25:1754-60.

37. Bradbury PJ, Zhang Z, Kroon DE, Casstevens TM. TASSEL: software for association mapping of complex traits in diverse samples. Bioinformatics. 2007;23:2633-5.

38. Tamura K, Stecher G, evolution DPBA. MEGA6: molecular evolutionary genetics analysis version 6.0. Mol Biol Evol. 2013;30:2725-9.

39. Raffaele S, Farrer RA, Cano LM, Studholme DJ, MacLean D, Thines M, et al. Genome evolution following host jumps in the Irish potato famine pathogen lineage. Science. 2010;330:1540-3.

40. DePristo MA, Banks E, Poplin R, Garimella KV, Maguire JR, Hartl C, et al. A framework for variation discovery and genotyping using next-generation DNA sequencing data. Nat Genet. 2011;43:491-8.

41. Knaus BJ, Grünwald NJ. Vcfr: a package to manipulate and visualize variant call format data in R. Mol Ecol Resour. 2017;17:44-53.

42. Ruijter JM, Ramakers C, acids WHN. Amplification efficiency: linking baseline and bias in the analysis of quantitative PCR data. Nucleic acids res. 2009;37:e45.

43. Pfaffl MW, Horgan GW, research LDNA. Relative expression software tool (RESTC) for group-wise comparison and statistical analysis of relative expression results in real-time PCR. Nucleic acids res. 2002;30:e36.

\section{Ready to submit your research? Choose BMC and benefit from:}

- fast, convenient online submission

- thorough peer review by experienced researchers in your field

- rapid publication on acceptance

- support for research data, including large and complex data types

- gold Open Access which fosters wider collaboration and increased citations

- maximum visibility for your research: over $100 \mathrm{M}$ website views per year

At $\mathrm{BMC}$, research is always in progress.

Learn more biomedcentral.com/submission 